\title{
UNASSERTABILITY AND THE APPEARANCE OF IGNORANCE
}

\author{
GEOFF PYNN
}

gpynn@niu.edu

\begin{abstract}
Whether it seems that you know something depends in part upon practical factors. When the stakes are low, it can seem to you that you know that $\mathrm{p}$, but when the stakes go up it'll seem to you that you don't. The apparent sensitivity of knowledge to stakes presents a serious challenge to epistemologists who endorse a stable semantics for knowledge attributions and reject the idea that whether you know something depends on how much is at stake. After arguing that previous attempts to meet this challenge fall short, I offer a new solution: the unassertability account. The account starts with the observation that high stakes subjects aren't in an epistemic position to assert. We generally presuppose that knowing is sufficient for epistemically proper assertion, but this presupposition only stands up to scrutiny if we draw a distinction between two notions of epistemic propriety, and we shouldn't expect ordinary speakers to draw it. A subject in a high stakes situation who fails to draw the distinction will be led by the sufficiency claim to treat anything she isn't in a position to assert as something she isn't in a position to know. The sensitivity of epistemically proper assertion to practical factors explains the merely apparent sensitivity of knowledge to stakes.
\end{abstract}

\section{INTRODUCTION}

Invariantists think that the truth conditions of knowledge claims are stable across contexts of utterance and assessment, at least so far as the contribution of the word 'knows' and its cognates go. Purists think that what's epistemically required to know something is fixed across practical situations. Purist invariantism has something like received view status in epistemology, so I'll call it traditionalism: denying invariantism requires endorsing an innovative contextualist or relativist account of the semantics of knowledge claims, while impurism involves a significant departure from the intuitively plausible idea that knowing that $\mathrm{p}$ isn't made easier by being in a situation where it doesn't matter very much whether $\mathrm{p}$ is true. ${ }^{\mathrm{I}}$

I Opponents of invariantism include contextualists such as Cohen (I988), Lewis (I996), and DeRose (2009), as well as relativists like MacFarlane (2005) (see MacFarlane 2009 and Stainton 20 Io for somewhat different versions of contextualism). Opponents of purism include Hawthorne (2004), Stanley (2005), and Fantl and McGrath (2009) (who introduced the term 'purism' to name the view they oppose and point out on page 28 that to many purism 'seems clearly true'). Versions of impurism are also proposed more cautiously by Grimm (2OII) and (even more cautiously) Schroeder (2OI2). 
Our ordinary thought and talk about knowledge suggest that either purism or invariantism has to go. For many ps, when the practical stakes related to the truth of $\mathrm{p}$ are low, it seems to us that we know that $\mathrm{p}$, but when the stakes go up, it seems to us that we don't. ${ }^{2}$ Variantists say that a change in stakes can affect what's required for a knowledge claim to be true. Impurists say that a change in stakes can affect what is epistemically required of a subject to know. Either path suggests a natural explanation for the sensitivity of the appearance of knowledge to stakes. But both are closed to the traditionalist.

Most traditionalists concede that in some range of situations it seems to us that we know things that we don't, in fact, know, or else that it seems to us that we don't know things that we do, in fact, know. Skeptical traditionalists say that the low-stakes appearance of knowledge is inaccurate. Moderate traditionalists say instead that the highstakes appearance of ignorance is misleading. ${ }^{3}$ The orientation of this paper is moderate traditionalism. So why, when the practical stakes are high, does it appear that we are ignorant of propositions that we are, in fact, in a position to know? This is the problem of the misleading appearance of ignorance.

After criticizing previous attempts to solve the problem on behalf of the moderate traditionalist, I will propose an alternative: the unassertability solution. The unassertability solution starts with an idea that has been used as a key premise in powerful arguments against moderate traditionalism: the principle that knowing is sufficient for epistemically proper assertion. ${ }^{4}$ But that principle only withstands scrutiny if we draw a distinction between a broad and a narrow notion of epistemically proper action. The distinction between broad and narrow propriety turns out to undermine the anti-traditionalist arguments. It also opens up an explanation for the high-stakes appearance of ignorance. The unassertability solution says that we tend to blur the distinction between broad and narrow propriety, with the result that in high stakes situations an accurate assessment that a speaker is not in a position to assert a proposition generates the misleading appearance that she is not in a position to know it.

I follow the common practice of characterizing purism and invariantism in terms of a subject's epistemic position. Purism says that whether a subject's epistemic position is sufficient for knowing that $\mathrm{p}$ does not vary directly with her practical situation; invariantism implies that whether a subject's epistemic position is sufficient for it to be true to attribute to her 'knowledge' that p does not shift with the context in which the attribution is made or assessed. A subject's epistemic position is understood to be a function of 'exclusively truth-relevant dimensions like how strong [her] evidence for/against $\mathrm{p}$ is, how reliable are the belief-forming processes available to [her] which would produce a belief that $\mathrm{p}$, how strong [her] counterfactual relations to the truth-value of $\mathrm{p}$ (how sensitive, how safe your available basis is for believing that p), etc.' (Fantl and McGrath 2009: 27).

2 There is controversy over what factors are most directly relevant to the fluctuation: is it a shift in practical stakes, salient error possibilities, contextually relevant questions, or something else? See Schaffer (2005) for discussion. Recent 'experimental' philosophy purports to cast doubt on the claim that knowledge attributions are as shifty as is typically assumed by participants in the debate. Knobe and Schaffer (2OI2) provide a good overview; for critical responses see DeRose (2OII) and Brown (2OI3). To the extent that this work casts doubt on the shiftiness of our knowledge attributions and denials, it undercuts the case against traditionalism. This paper presupposes that the appearance of knowledge is sensitive to practical situations; the question is how the traditionalist should account for this fact.

3 I use the term 'ignorance' in a somewhat stipulative sense to mean what could more awkwardly but accurately be called 'non-knowledge'; this usage has been common in epistemology since at least Unger (1975). For a persuasive case that ignorance, properly speaking, is not (merely) non-knowledge, see Peels (20I0).

4 See, for example, DeRose (2009: ch. 3), Hawthorne (2004), and Schaffer (2008). 


\section{BOB AND CAROL AND TED AND ALICE}

Cases of the relevant sort are quite familiar. Here is a pair of cases of the familiar kind:

The set-up. Bob and Carol have been invited to a dinner party at Ted and Alice's tonight; only Bob can go, since Carol has to work the night shift. They decide to make cupcakes. Bob will take most to the dinner party, and Carol will take the rest to work. The only spice their recipe calls for is cardamom. They follow the recipe, and bake several dozen, but decide to experiment with the last bit of batter by adding some cinnamon. After baking the rest, they carefully set the cinnamon cupcakes aside to try later.

At the office. Carol announces to her coworkers that she's brought cupcakes. 'Ooh,' exclaims her friend, 'I love cupcakes!' But just before taking a bite, she pauses to ask, 'These smell spicy - do they have cinnamon?'

'No, they only have cardamom,' Carol answers.

'Okay, because I really don't like cinnamon.'

'Bob and I baked them ourselves this morning,' Alice says, 'so I know that they don't have cinnamon in them.'

At the dinner party. Bob hands Alice his box of cupcakes. 'Freshly baked!' he declares. 'Ooh,' exclaims Alice, 'we always love your desserts!' But then she frowns. 'I haven't told you yet, but last week Ted had to go to the emergency room - it turns out that he's developed a rare severe cinnamon allergy! The doctors say that it can be fatal; he's lucky to have survived the attack. So now we have to be extremely careful about what he eats. These don't have cinnamon in them, do they?'

'Well,' Bob says, 'I'm quite sure they don't: the only spice the recipe calls for is cardamom. But we did add cinnamon to some of the batter at the end, just as an experiment. We set those last few cupcakes aside, and I'm confident none of them got mixed in with the rest. But you know, I suppose it is possible that they did. I suppose it's even possible that we accidentally put some cinnamon in the rest, though I seriously doubt it. Still, I guess there's a slight chance the cupcakes could have cinnamon in them. So I don't know that they don't.'

'Do you think Carol would know?'

'No, we were together the whole time. She doesn't know either.'

At the office, Carol asserts (I); at Alice's, Bob asserts (2) and (3):

(I) I know that the cupcakes don't have cinnamon in them.

(2) I don't know that the cupcakes don't have cinnamon in them.

(3) Carol doesn't know that the cupcakes don't have cinnamon in them.

Considered with respect to the conversation where it's uttered, each assertion is natural and seemingly true. A moderate will say that given Carol's epistemic position, (I) is 
true. Invariantism implies that $(\mathrm{I})$ and $(3)$ are contradictory, so if $(\mathrm{I})$ is true, $(3)$ is false. ${ }^{5}$ Moreover, Carol and Bob have the same basis for believing that the cupcakes don't contain cinnamon, and Bob has no evidence against this proposition that Carol lacks. If their epistemic positions with respect to the cinnamon proposition are identical, purism implies that Carol is in a position to know it only if Bob is. Hence given purism, (I) makes (2) highly doubtful. But if (I) is true and (2) and (3) are false, why do (2) and (3) seem true when considered with respect to Bob's conversation?

Previous attempts to answer this question on behalf of moderate traditionalism fall into three families. Pragmatic solutions rely on the idea that assertions typically convey information beyond the contents asserted to explain our false knowledge denials. ${ }^{6}$ If false knowledge denials convey relevant information in high stakes contexts, they may be appropriate even though false. One challenge for this strategy is that high stakes knowledge denials seem true, and not merely appropriate. There is no general tendency to mistake conversational propriety for truth: assertions that are hyperbolic, meiotic, metaphorical, ironic, and sarcastic can all be appropriate while clearly appearing, upon even momentary reflection, to be false. In these cases, attention to the distinction between the literal content of the speaker's assertion and what she communicates by making the assertion makes it easy to see that the former is false. Moreover, unlike standard examples of appropriate but false assertion, high stakes knowledge denials seem true even in thought. From the perspective of a high stakes situation, subjects seem not to know. It is not clear how the communicative effects of an assertion should affect how its content appears in silent contemplation. ${ }^{7}$

Timothy Williamson instead offers an illusion solution. He says that when we focus on unusual possibilities of error, we tend to give them more weight in our judgments about knowledge than is warranted, thereby experiencing 'an illusion of epistemic danger' (Williamson 2005: 225-6). ${ }^{8}$ But this doesn't seem like a plausible diagnosis of Bob's case. Illusory appearances are resilient even for subjects who recognize them to be misleading. Bob's attitude towards the risk that the cupcakes contain cinnamon doesn't rest on such an appearance. With additional confirmation that the unlikely cinnamon scenarios he mentions didn't occur, the epistemic appearances would change. For example, he would treat a

5 For the purposes of this paper I'm treating some views that accept that 'knows' is semantically stable as versions of variantism; for example the view that circumstances of evaluation contain a parameter that varies with epistemic standards (MacFarlane 2005, 2009; Brogaard 2008) or that different contents can be asserted by distinct utterances of a semantically invariant knowledge-attributing sentence (Stainton 20I0).

6 See, for example Rysiew (200I, 2007), Black (2005), Brown (2006) and Hazlett (2007). For criticism, see DeRose (2009: I I 8-24), Fantl and McGrath (2009: 28-42), Iacono (2008), and MacFarlane (2005: 207-8).

7 Rysiew (2007) suggests that speakers and listeners typically blur the boundaries between the information semantically encoded by a knowledge claim and that (merely) pragmatically conveyed by its utterance. Rysiew's suggestion could help a proponent of the pragmatic solution explain why high stakes knowledge denials seem true even in thought.

8 More specifically, he proposes that the illusion of epistemic danger is an effect of the availability heuristic, which leads subjects to overestimate the likelihood of situations that can be easily imagined or are especially salient.. Nagel (20I0) persuasively criticizes Williamson's appeal to the availability heuristic on empirical grounds. But the core of the illusion proposal doesn't involve the availability heuristic. The suggestion is simply that when attending to possibilities of error we generally ignore, we tend to experience an illusion of epistemic danger. 
lab test indicating that the cupcakes didn't contain cinnamon as conclusive, and so regard himself as knowing. More generally, his assessment of his epistemic situation indicates high cognitive function and epistemic responsibility, unlike a faulty judgment based on an illusory appearance. He methodically reviews his evidence and responds to Carol with a degree of caution that seems entirely appropriate given the high stakes involved.

In addition, Williamson's proposal implies that the speaker overestimates the likelihood that the subject has made an error. But this description is also inapt in Bob's case. He acknowledges the chance that he's wrong to be quite small. The high stakes lead him to take his epistemic risks seriously, but taking small risks seriously is not the same as treating them as larger than they really are. Rather, his mistake, from the perspective of the moderate traditionalist, is to judge that the tiny chance of error is incompatible with knowing.

Lost attitude solutions say that when the stakes go up, subjects tend to lose the doxastic attitude required for knowledge. Jennifer Nagel has worked out a version of this solution in brilliant detail. Nagel says that subjects in high stakes situations experience a high 'need for closure'; i.e., they require more information before forming settled beliefs than do subjects in low stakes situations (Nagel 2008). She calls the force underlying this phenomenon 'epistemic anxiety' (Nagel 20II). Perhaps, experiencing heightened epistemic anxiety about the cinnamon, Bob refrains from forming a settled belief in the proposition that the cupcakes are cinnamon-free. If he lacks a settled belief, he doesn't know, and so (2) is true. ${ }^{9}$

One objection to Nagel's proposal is that Bob seems capable of regarding himself as having a settled belief while still thinking that he doesn't know. He could naturally say that while he believes that there's no cinnamon, he doesn't know. ${ }^{\text {Io }}$ Moreover, the lost attitude account doesn't explain why it seems to Bob that Carol doesn't know. Nagel proposes accounting for the third-person appearance of ignorance in terms of a bias called 'epistemic egoism' that leads us to regard others as if they had more in common with us than they do when attributing mental states to them (Nagel 20I0). Bob and those of us sympathetically imagining his conversation may treat Carol as if she 'shared our heightened need for evidence' (Nagel 2OII: 425). This egoistic projection could result in a mistaken impression that $(3)$ is true; Carol would appear to have adopted the attitude of knowing without having acquired the additional evidence demanded by her (projected)

9 Nagel's diagnosis echoes Kent Bach's suggestion that in high stakes situations our 'threshold for (confidently) believing' goes up, meaning that we require especially strong evidence for a proposition before we are willing to confidently believe it (Bach 2005).

Io This objection to the lost attitude proposal may not be very powerful. For one thing, concessive belief reports such as these do not obviously constitute claims about the speaker's settled or confident beliefs, especially in circumstances in which the subject also articulates grounds for doubt. They may instead constitute hedged expressions of relative confidence. Suppose that I recall that Sasha signed up for my class, though I am quite unsure about whether she's still in the class - a number of students dropped out after the first week, and she may have been one of them. I have no settled belief about whether she's in the class. But in answer to a question about whether she is in the class I could naturally and appropriately reply, 'I believe that she is, though I am not sure.' Moreover, though epistemologists typically use the word 'belief' and its cognates to denote the doxastic attitude required for knowledge, there is room to doubt that the attitude we ordinarily denote with 'belief' is the attitude required for knowledge. If the required attitude is stronger (e.g., if it is being sure (Ayer 1956: 34)), then Bob's report, even if it did constitute a claim about his beliefs, may not imply that he has the attitude required for knowledge. Taking this suggestion on board, a slight modification to the lost attitude account - to say that subjects in high stakes situations refrain from adopting the attitude of knowledge - would reconcile it with the propriety of high stakes claims to believe but not to know. 
heightened epistemic anxiety. ${ }^{\mathrm{II}}$ Though ingenious, the proposal is tendentious. I find no impression that Carol is in a state of heightened epistemic anxiety. Nor do I feel any inclination to treat her attitude as epistemically irresponsible: given her epistemic position and practical situation, she seems to have just the doxastic attitudes she ought to have. Of course if Nagel is right that our judgments are distorted by a cognitive bias we should be alert to the possibility that our introspective assessment of the basis for those judgments is inaccurate. Still, it is desirable to have an explanation for (3)'s apparent truth that does not rest on the claim that we treat Carol as being either in a state of heightened epistemic anxiety or epistemically irresponsible.

Moreover even granting Nagel's egoistic projection explanation for the apparent truth of (3), the problem of false denials persists. Bob also seems not to be in a position to know. From the perspective of his conversation, it seems that even if he did have the attitude required for knowledge, he still wouldn't know. Indeed, in his conversation with Alice an assertion of (2a), though a bit clunkier, would be just as apparently true as his assertion of (2):

(2a) I'm not in a position to know that the cupcakes don't have cinnamon in them.

If Bob lacks the attitude of knowledge, perhaps this is because it appears to him that his epistemic position doesn't warrant it. The moderate traditionalist must treat this appearance as misleading. And in response to Alice's last question Bob could assert:

(3a) Carol isn't in a position to know that the cupcakes don't have cinnamon in them.

Given that $(\mathrm{I})$ is true, $(3 \mathrm{a})$ is false. Thus we have another false appearance to account for: that, from the perspective of the high stakes conversation, neither Bob nor Carol is in a position to know.

\section{SIX DESIDERATA FOR A SOLUTION}

The challenges faced by the three solutions just discussed reflect six aspects of the high stakes appearance of ignorance that an adequate moderate traditionalist solution should account for:

Semantics. The high stakes appearance of ignorance is not diminished by careful attention to the distinction between the content asserted by a knowledge denial and the other communicative effects of asserting that content.

I I It is easy to suppose that Carol has the attitude of knowledge without diminishing the impression that (3) is true. Bob could felicitously report that Carol, though sure, doesn't know; or that while she may think she knows, she doesn't. So the error is not plausibly diagnosed in terms of an egoistic projection of the speaker's own reluctance to adopt the attitude of knowledge. Nagel's proposal is that Bob projects his heightened epistemic anxiety onto Carol but not his caution about adopting the attitude of knowledge. If he takes her to have adopted the attitude of knowledge without engaging in the further effort demanded by her (projected) heightened need for evidence, then he'll judge her to have done so hastily and hence to have violated 'an invariant standard censuring hasty or distracted thought' (Nagel 2010: 304). The proposal yields a tidy explanation of the apparent truth of (3) that not only does not require supposing that Bob treats Carol as lacking the attitude of knowledge, but requires supposing that he treats her as having it. 
Thought. The high stakes appearance of ignorance arises in thought; it seems that the subject doesn't know, not merely that she can't truly assert that she knows or that she can truly assert that she doesn't know.

Responsibility. The high stakes appearance of ignorance reflects epistemically responsible caution about the subject's epistemic position.

Accuracy. The high stakes appearance of ignorance reflects an accurate assessment of the subject's epistemic risks.

Projection. From the perspective of a high stakes situation, it seems that third parties in similar epistemic positions don't know either, even if they aren't taken to be in high stakes situations.

Position to Know. The high stakes appearance of ignorance is accompanied by the appearance that the subject is not in a position to know.

A fully satisfactory solution to the problem of false denials should explain each of these aspects. The pragmatic solution struggles with Persistence and Thought; the illusion solution leaves Responsibility unexplained and - on Williamson's formulation, at least - is incompatible with Accuracy; the lost attitude solution predicts neither Projection nor Position to Know. In what follows, I'll lay out a solution that predicts and explains all six aspects of the high stakes appearance of ignorance. But first, a detour through a powerful argument against moderate traditionalism.

\section{UNASSERTABILITY AND IGNORANCE}

The apparent truth of (2) and (3) can be bolstered by an argument. ${ }^{\mathrm{I} 2}$ It is plausible that a speaker who knows that $\mathrm{p}$ is in an epistemic position sufficient for making an epistemically proper assertion that $\mathrm{p}$. The sufficiency principle can be defended by appeal to the proposal that the constitutive norm of assertion is that one should assert only what one knows; if there are no other rules specific to assertion, anyone who knows that $\mathrm{p}$ is in an epistemic position to assert that $\mathrm{p} .{ }^{\mathrm{I}}$ It can also be defended by appeal to any proposal about the constitutive norm of assertion that specifies a condition satisfied by anyone who knows. ${ }^{14}$ If the constitutive rule of assertion is that one must satisfy $\mathrm{C}$ in order to assert that $\mathrm{p}$, and $\mathrm{C}$ is a condition satisfied by anyone who knows that $\mathrm{p}$, then anyone who knows that $\mathrm{p}$ is in a position to assert that $\mathrm{p}$. Finally, it can be defended by appeal to our conversational practices. We recommend speakers as sources of assertions on the basis of our presumption that they are in a position to know and criticize speakers whose assertions would have been useful when we find out

I 2 This argument resembles that given by DeRose (2002; for an updated discussion, see DeRose 2009: ch. 3 ).

I3 See Williamson (2000: ch. II) for this proposal.

I4 For example, the Truth Rule (Weiner 2005), the Justified Belief Rule (Kvanvig 2009), the Belief Rule (Bach 2008), and the Rational Credibility Rule (Douven 2006) would all, given very plausible assumptions and treated as the sole norm governing assertion, imply that a speaker who knows is in a position to assert. 
that they were in a position to know. Both practices suggest that we tacitly accept the sufficiency principle. ${ }^{\mathrm{I}}$

Yet in his conversation with Alice, Bob would clearly do something epistemically improper by asserting that the cupcakes are cinnamon-free. Having acknowledged the slight but real chance that he's mistaken, and fully cognizant of the stakes involved, he could not then properly assert to Alice that the cupcakes have no cinnamon in them. If being in a position to know suffices for being in a position to assert, then we can infer ignorance from unassertability:

(UI) In his conversation with Alice, Bob is not in an epistemic position to assert that the cupcakes are cinnamon-free.

(U2) If a speaker is in a position to know that $\mathrm{p}$, then he or she is in an epistemic position to assert that $\mathrm{p}$.

$\left(\mathrm{U}_{3}\right)$ So, in his conversation with Alice, Bob isn't in a position to know that the cupcakes are cinnamon-free.

Since Carol and Bob are in the same epistemic position with respect to the cinnamon proposition, $\left(\mathrm{U}_{3}\right)$ together with traditionalism implies that she is not in a position to know either.

How should the moderate traditionalist respond to this argument? It is not appealing to say that Bob would do nothing epistemically wrong by asserting the cinnamon proposition in his conversation with Alice. It is one thing to claim that Bob's high stakes knowledge denials are, contrary to appearances, false. It's another to say that Bob's assertion to Alice that the cupcakes are cinnamon-free would be epistemically impeccable. We may be mistaken about whether a subject knows without being mistaken about whether a particular speech act would be proper. If moderate traditionalism indicted our capacity to assess the propriety of assertions in high stakes situations, it would incur heavier theoretical costs than just the problem of the misleading appearance of ignorance. The more obvious line of resistance is to reject $\left(\mathrm{U}_{2}\right)$. Some traditionalists do argue that knowledge is insufficient for epistemically proper assertion. ${ }^{\mathrm{I} 6}$ But is there another way for the moderate traditionalist to resist the unassertability argument? In the next section I'll offer a way to endorse each premise in a form that renders the argument invalid. This path of resistance will lead, in the following section, to a new solution to the problem of false denials.

\section{HIGH STAKES UNASSERTABILITY}

In doing one thing, you often do others as well. By practicing a piece on the piano you commit it to memory; by cycling down the path you commute to work; by harrumphing

I 5 Though see Brown (2010) for criticisms of the use of such conversational practices as evidence for the sufficiency claim.

I6 See Brown (20I0) and Lackey (20II). Though Stanley (2005) articulates a version of impurism, Stanley (2008) argues on grounds available to purists that certainty is required for epistemically proper assertion. On the assumption (which Stanley makes) that being in a position to know does not require being certain, this position would also provide a basis for rejecting (U2). See also Pynn (forthcoming), which defends the idea that epistemically proper assertion requires sensitive belief. If sensitive belief is not required for knowledge, the sensitive belief requirement would also underwrite the rejection of $\left(\mathrm{U}_{2}\right)$. 
you express your irritation. ${ }^{17}$ Moreover, what you do by doing something depends upon the circumstances in which you do it. In different circumstances, you would practice the piece without committing it to memory (because of squealing children tumbling through the living room); cycle down the path without commuting (because you have the day off); or harrumph without expressing your irritation (because you are acting in a play). The circumstances in which you act determine, in large part, all of what you thereby do. As Arthur Danto says, 'We must read the identity of the action from the context of its execution' (Danto I973: ix).

Assertion is no exception: by asserting you often do other things as well, though what else you do depends upon your circumstances. You can greet a friend by asserting that you're happy to see her, dismiss an objection by asserting that it rests on a claim that's been refuted, insult your host by asserting that his cooking is incompetent, or commit heresy by asserting that God is not triune. ${ }^{{ }^{8}}$ In different circumstances the same assertions may have constituted different doings. In culinary school an assertion that someone's cooking is incompetent may constitute constructive criticism, not an insult; had early church councils had different outcomes, an assertion that God is not triune might have constituted an expression of Christian orthodoxy, not a commission of heresy; and so on.

With these observations in mind, we can distinguish two conceptions of an epistemically proper assertion. I'll say that an assertion is narrowly epistemically proper just in case it is epistemically proper qua assertion. An assertion's narrow propriety concerns the question: ignoring whatever else the speaker would do by asserting that $\mathrm{p}$, is she in an epistemic position to assert that $\mathrm{p}$ ? The concept of narrow propriety may be elaborated with the idea that there is an epistemic rule specific to assertion. On this way of conceiving of narrow propriety, an assertion is narrowly proper just in case it violates no assertionspecific epistemic rule. For example, if the Knowledge Rule is the only epistemic rule specific to assertion, then an assertion is narrowly epistemically proper if and only if it is known. Weaker rules that specify conditions satisfied by those who know that $\mathrm{p}$ will also imply that a speaker who knows that $\mathrm{p}$ is in a position to make a narrowly epistemically proper assertion that $\mathrm{p}$.

By contrast an assertion is broadly epistemically proper just in case, by asserting, the speaker does nothing that she's not in an epistemic position to do. Our practice of assessing action in terms of epistemic propriety is hardly limited to assertion. You shouldn't venture out on to the ice without good evidence that it's thick enough to hold your weight; you shouldn't take a cake out of the oven unless you have good evidence that it's done. ${ }^{9}$ If

I Danto's related distinction between 'mediated' actions - i.e., those one performs by performing other actions - and 'basic' actions - i.e., those that are not mediated - has received a great deal of attention (Danto I973); see Sandis (2010) for a good overview of the literature. In the present discussion, the notion of a basic action is unimportant: most of the examples I'll be concerned with involve mediated actions performed by other mediated actions.

I 8 What Searle calls 'indirect speech acts' are instances of this phenomenon, though I do not wish to say that everything one does by asserting is thereby a speech act, even an indirect one (Searle I969). Greeting, dismissing, insulting, and so on can all be accomplished without speaking, and we needn't characterize them as indirect speech acts simply because they can also be accomplished by speaking. But this is probably a merely terminological quibble. Bertolet (1994) makes a nice case for skepticism about the existence of indirect speech acts.

I9 Fantl and McGrath (2009) credit the ice example to Mark Migotti; the cake example is from Hawthorne and Stanley (2009). 
by asserting you do something else that you're not in an epistemic position to do, your assertion will exhibit an epistemic impropriety not traceable to any epistemic rules specific to assertion, or the propriety of your assertion qua assertion. An assertion that is broadly proper will also be narrowly proper, but since one can do something epistemically improper by asserting without doing anything improper qua asserting, an assertion that is narrowly proper may not be broadly proper.

The principle that being in a position to know $\mathrm{p}$ is sufficient for being in a position to assert $\mathrm{p}$ can thus be understood in two ways. On the narrow construal, the claim is that a speaker in a position to know $\mathrm{p}$ is in a position to make a narrowly epistemically proper assertion that $\mathrm{p}$. On the broad construal, the claim is that a speaker who knows that $\mathrm{p}$ is in a position to assert that $\mathrm{p}$ without doing anything she's not in an epistemic position to do.

The broad sufficiency claim is not plausible. The sufficiency principle draws support from popular views about the constitutive norm of assertion, as well as conversational practices that indicate that ordinary speakers presuppose that knowing puts them in a position to assert. But while these sources support the idea that known assertions are epistemically proper qua assertions, they give us no reason to think that any act whatsoever that one performs by asserting is epistemically proper so long as the speaker knows the content she asserts. Earlier in this section I mentioned four things one may do by asserting: greet a friend, dismiss an objection, insult a cook, commit heresy. That is a very small sample. Given the infinite variety of possible conversational circumstances, it seems there is a limitless number of things one may do by asserting. It would be surprising to find that for any of the many $\varphi$ s one may apparently perform by asserting, it is in fact possible to $\varphi$ by asserting that $\mathrm{p}$ only if knowing that $\mathrm{p}$ is sufficient for epistemically proper $\varphi$-ing.

Three families of cases furnish natural counterexamples to the broad sufficiency claim. First, by asserting that $\mathrm{p}$, one may conversationally implicate information one is not in a position to communicate. For example, by asserting that there is a gas station around the corner, a speaker may implicate that gas is available around the corner. If the speaker has good reason to think that the gas station is long abandoned, she will have done something epistemically improper by asserting that there is a gas station around the corner, even if she knows that there is a gas station around the corner. Of course the speaker could cancel her implicature, and so assert without doing anything epistemically improper; the point is that if she allows the implicature to stand, by asserting she will have done something epistemically improper despite knowing the content she asserts.

Second, by asserting that $\mathrm{p}$ one may express an attitude towards $\mathrm{p}$ one ought not, epistemically, to express. For example, in some conversations an unusually demanding epistemic standard may become salient. In such a conversation a flat-out assertion that $\mathrm{p}$ is liable also to constitute an expression of an especially high degree of certainty that $\mathrm{p}$. If the speaker knows that $\mathrm{p}$ but is not in an epistemic position that warrants especially high certainty that $\mathrm{p}$, she will do something epistemically improper by asserting that $\mathrm{p}^{20}$

Third, assertions may take on unusual significance by the adoption of special conventions. For example, suppose that you and your friend are poker cheats who have a code for communicating surreptitiously to each other during the course of play. One element of the code is this: whenever one of you wants the other one to fold, you're to make an

20 This type of case may include assertions that constitute high-strength assertoric acts such as guaranteeing or swearing; guaranteeing is discussed in detail in the next section. 
observation about the temperature in the room. Of course your success as cheaters requires that you'll instruct your partner to fold only if you have good reason for doing so. During the course of the game, you notice that it's getting very warm in the room. If you're not in an epistemic position to instruct your partner to fold - you've been negligent in observing the other players' hands - you'd do something epistemically improper by asserting that it's warm in the room, despite knowing that it's warm in the room.

In each type of case, there is some $\mathrm{p}$ such that the speaker knows that $\mathrm{p}$ but would do something broadly epistemically improper by asserting that $\mathrm{p}$. They illustrate that being in a position to know that $\mathrm{p}$ does not ensure that one's epistemic position with respect to $\mathrm{p}$ is strong enough to make a broadly epistemically proper assertion. But they provide no evidence against the narrow sufficiency claim. In each case, the epistemic impropriety of the assertion derives from the epistemic impropriety of something else the speaker would do by asserting. So provided the sufficiency principle is understood as a claim about narrow propriety, its plausibility is not undermined by such cases:

$\left(\mathrm{U}_{2} \mathrm{~N}\right)$ If a speaker is in a position to know that $\mathrm{p}$, then she is in a position to make a narrowly epistemically proper assertion that $\mathrm{p}$.

$\left(\mathrm{U}_{2} \mathrm{~N}\right)$ implies that a known assertion is narrowly epistemically proper, but not that it proper tout court. (UI) implies that Bob would do something epistemically improper by asserting that the cupcakes are cinnamon-free in his conversation with Alice. But unless his assertion would be narrowly improper, ( $2 \mathrm{~N}$ ) will not license the conclusion that he is not in a position to know that the cupcakes are cinnamon free. If we have a way to diagnose the impropriety of Bob's assertion in terms of what else he would do by asserting, we have a way to disarm the unassertability argument. Is such a diagnosis available?

\section{GUARANTEEING AND OTHER EPISTEMICALLY DEMANDING CONVERSATIONAL ACTS}

John Turri argues that in high stakes contexts, speakers who make assertoric utterances thereby guarantee (Turri 20IO). To properly guarantee that $\mathrm{p}$, you need to be in a stronger epistemic position with respect to $\mathrm{p}$ than you do to properly assert that $\mathrm{p}$; on Turri's favored view, proper guaranteeing requires knowing that you know. Suppose that Bob's assertion would constitute a guarantee that the cupcakes are cinnamon-free. If he doesn't know that he knows this, then by asserting he would do something epistemically improper, even if he knows and hence is in a position to make a narrowly proper assertion. I'm not convinced that Turri's 'knowing-that-you-know' account of proper guaranteeing is satisfactory, so I won't rely on it further. ${ }^{2 I}$ The key idea is that to properly guarantee that $\mathrm{p}$ requires a stronger epistemic position with respect to $\mathrm{p}$ than does

2 I Here is one obstacle that the KK account of guaranteeing presents when put to work in an explanation for the impropriety of Bob's high-stakes assertion. Bob and Carol are ex hypothesi in the same epistemic position with respect to the cinnamon proposition. Thus it is plausible that Carol is in a position to know that she knows it only if Bob is in a position to know that he knows it. But Carol is in a position to assert (I). Given the Knowledge Rule of Assertion - i.e., the rule that one must assert only what 
properly asserting that $\mathrm{p}$; in particular, that it requires more than being in a position to know that $\mathrm{p}$, and something that Bob lacks. ${ }^{22}$

Turri's proposal gives us a way to treat Bob's assertion as merely broadly improper: though he knows that $\mathrm{p}$, in his conversation with Alice his assertion would constitute a guarantee, which he is not in an epistemic position to make. If so, we have a rationale for treating (UI) as a claim about broad propriety:

(UIB) In his conversation with Alice, Bob is not in an epistemic position to make a broadly proper assertion that the cupcakes are cinnamon-free.

Since broad impropriety does not imply narrow impropriety, (UIB) and ( $\mathrm{U}_{2} \mathrm{~N}$ ) do not together imply $\left(\mathrm{U}_{3}\right)$. This treatment of the premises gives us a way to disarm the unassertability argument without rejecting the sufficiency principle.

One might object that if Bob's assertion would be improper only in virtue of constituting a guarantee, he should be able to assert properly by disavowing an intention to guarantee: by saying, for example, 'The cupcakes don't have any cinnamon, though I don't guarantee it.' But such a clarification would not make the assertion epistemically proper. Since the assertion's epistemic impropriety would survive an explicit disavowal of the speaker's intention to guarantee, it must attach to the assertion qua assertion; i.e., it must be narrow impropriety.

However, the objection makes two questionable assumptions. The first is that to assert while disavowing an intention to guarantee is sufficient to assert without guaranteeing. When circumstances are such that by asserting one would also $\varphi$, intending not to $\varphi$ is not generally sufficient for asserting without $\varphi$-ing. Indeed, whether an assertion constitutes a $\varphi$-ing can lie quite outside the speaker's control. The assertions of a witness who has taken an oath to tell the truth constitute sworn testimony whether or not she intends them to. She cannot refrain from offering sworn testimony by mentally crossing her fingers. Perhaps guaranteeing is like this: in high stakes conversations one may be unable to

one knows - she is in a position to know that she knows the cinnamon proposition. So one of the following is false: (I) you should assert only what you're in a position to know, (2) when $S$ and $S^{*}$ are in the same epistemic position with respect to $\mathrm{p}$, either both are in a position to know that she herself knows, or neither is, or (3) proper guaranteeing requires being in a position to know that you know. Since Turri presents his account as one on which high stakes unassertability is compatible with the Knowledge Rule, rejecting (I) is unappealing. I won't pretend that $(2)$ is clearly true, but defending the KK story here would require an argument that Bob and Carol, though in the same epistemic position with respect to the cinnamon proposition, are in different epistemic positions with respect to the higher-order proposition. Turri himself says that knowing that you know constitutes a 'greater epistemic achievement than merely knowing' (2010: p. 87, fn. I 5); it is not obvious how two subjects could be in the same epistemic position with respect to $\mathrm{p}$ yet one be creditable with a greater epistemic achievement with respect to $\mathrm{p}$ than the other.

More precisely, Turri's view is that in high stakes circumstances by making an assertoric utterance one makes a guarantee rather than an assertion (Turri 20I0: 88-9, esp. footnote 18 ). On this picture Bob would not guarantee by asserting, because he would not assert; he would rather guarantee by making an assertoric utterance. But this element of Turri's proposal is inessential: one could also hold that in high stakes circumstances a speaker guarantees by asserting, or that guaranteeing is a special kind of asserting. This would echo Williamson's suggestion that swearing - a speech act with 'a more stringent evidential norm' than that governing assertion - may simply be a 'solemn way of asserting' (Williamson 2000: 244-5). 
prevent one's assertoric utterance from constituting a guarantee, even if one intends it as a (mere) assertion. If intending to assert without guaranteeing is insufficient to prevent Bob's assertion from constituting a guarantee, then disavowing an intention to guarantee won't restore his assertion to epistemic propriety.

The second assumption that the objection makes is that the impropriety of the utterance would be epistemic in nature. This may be doubted. When a guarantee is needed or expected, a mere assertion is liable to be pointless or misleading. Thus someone who asserts while explicitly disavowing the intention to guarantee in such a circumstance is apt to express a stubbornly uncooperative attitude, or else to signal confusion about the conversational demands. If, in Bob's conversation, a guarantee is needed or expected, an assertion of 'The cupcakes don't have any cinnamon, though I don't guarantee it' would be pragmatically defective. This defect would enable us to explain the assertion's impropriety without reference to any epistemic impropriety. If the impropriety of the conjunction can be explained in these more broadly pragmatic terms, it does not provide evidence that Bob's assertion that the cupcakes don't have any cinnamon is narrowly improper.

Turri's suggestion about guaranteeing is not the only way to diagnose the impropriety of Bob's assertion as being merely broad. There are other candidates for the epistemically improper action Bob's assertion would constitute in his conversation with Alice. For example, by asserting he may also:

- Express an attitude of certainty towards the cinnamon proposition.

- Promise Alice that Ted won't have an adverse reaction to the cupcakes.

- Convince or persuade Alice to give Ted a cupcake. ${ }^{23}$

Recognizing that there is a tiny but conversationally relevant chance that the cupcakes have cinnamon in them, Bob is not in a position to express certainty. Similarly, he's not in a position to promise Alice that Ted won't have an adverse reaction to eating them. And given the risks, his epistemic position doesn't justify him in convincing Alice to give Ted a cupcake. Independently of Turri's proposal about guaranteeing, then, the moderate traditionalist who wishes to respect the sufficiency principle has numerous paths to resist the argument from unassertability to ignorance.

\section{UNASSERTABILITY AND THE APPEARANCE OF IGNORANCE}

Now we return to the appearance of ignorance. The distinction between narrow and broad propriety opens up a new explanation for the appearance of ignorance in cases like Bob's. According to the unassertability solution, Bob recognizes that his epistemic position with respect to the cinnamon proposition is insufficient for properly asserting it. He also has the sufficiency principle among his background presuppositions. His

23 Unlike asserting, expressing, and promising, convincing and persuading are examples of what Austin calls perlocutionary acts (Austin I962: IOI). Perlocutionary acts essentially involve the production of certain effects in listeners. The broad propriety of a given assertion may turn on the propriety of causing its perlocutionary effects; if by asserting something I persuade you to shoot someone, my assertion may be broadly improper because I ought not to bring about the shooting, even if it is entirely proper $q u a$ assertion. The suggestion here is that the epistemic impropriety of a perlocutionary act can undermine the broad epistemic propriety of the assertion used to accomplish it. 
recognition of the epistemic impropriety of the assertion, together with his acceptance of the sufficiency principle, generates the impression of ignorance. If the impropriety would be merely broad, the appearance may be inaccurate. When a subject's epistemic position with respect to $\mathrm{p}$ is sufficient for narrow but not broad assertability, speakers are apt to experience a misleading impression of ignorance.

Not every broadly improper but narrowly proper assertion will appear unknown, even to speakers who are sensitive to its impropriety and presuppose the sufficiency principle. If an assertion that $\mathrm{p}$ would be broadly improper because it would generate an unwarranted implicature that q, we should not expect the speaker to judge that she doesn't know that p. The key factor in Bob's case is that the broad impropriety of asserting p results from a weakness in his epistemic position with respect to $p$. The unassertability solution says that when a weakness in the speaker's epistemic position with respect to $\mathrm{p}$ would make her assertion that $\mathrm{p}$ improper and she presupposes that being in a position to know is sufficient for being in a position to assert, she will tend to judge that she is not in a position to know that $\mathrm{p}$. When, in fact, she is in a position to know that $\mathrm{p}$ - and hence her assertion would be merely broadly improper - this judgment will be inaccurate.

The solution credits Bob with awareness that:

(*) Due to a weakness in my epistemic position with respect to p, I should not assert that $\mathrm{p}$.

As we have seen $(*)$ can be made true in two different ways:

$(* \mathrm{~N})$ Due to a weakness in my epistemic position with respect to $\mathrm{p}$, asserting that $\mathrm{p}$ would be narrowly epistemically improper.

$\left({ }^{*} \mathrm{~B}\right)$ Due to a weakness in my epistemic position with respect to $\mathrm{p}$, asserting that $\mathrm{p}$ would be (merely) broadly epistemically improper.

In Bob's conversation, $(*)$ is true in virtue of $\left({ }^{*} \mathrm{~B}\right)$, and not in virtue of $(* \mathrm{~N})$. The capacity to differentiate cases where $\left({ }^{*} \mathrm{~B}\right)$ is true from cases where $\left({ }^{*} \mathrm{~N}\right)$ is true presupposes a grasp of a philosophically sophisticated distinction that we can hardly expect ordinary speakers to draw, especially in the hurly-burly of ordinary conversation. Moreover, the distinction is of little practical significance. Whether $\left({ }^{*}\right)$ is true because of $\left({ }^{*} \mathrm{~B}\right)$ or $\left({ }^{*} \mathrm{~N}\right)$, the actionguiding upshot is the same: the speaker ought not to assert $\mathrm{p}$ without first improving her epistemic position with respect to p. For ordinary speakers to avoid epistemically improper assertions, sensitivity to impropriety tout court is enough.

Not only is there no practical significance in distinguishing between cases where $\left({ }^{*} \mathrm{~N}\right)$ is true and cases where $\left({ }^{*} \mathrm{~B}\right)$ is true, the distinction will remain elusive even to speakers who are sophisticated enough to draw it. When asserting that $\mathrm{p}$ would be broadly improper, asserting that $\mathrm{p}$ is known would be even more emphatically improper. So in circumstances where a speaker cannot assert that p because (for example) she is not in an epistemic position to guarantee that $\mathrm{p}$, she will also be unable to assert that she knows or is in a position to know p. Given the sufficiency principle, this means that when a speaker is in a position to make a narrowly proper (because known) assertion, but not a broadly proper one (due to a weakness in her epistemic position with respect to p), she will be in no position to assert that this is the case. For such a speaker to provide an accurate description of her position vis-à-vis p's assertability would require making an assertion that is, in the circumstances, forbidden on epistemic grounds. 
Even though the distinction between $\left({ }^{*} \mathrm{~B}\right)$ and $\left({ }^{*} \mathrm{~N}\right)$ is elusive and practically insignificant, blindness to it will, together with the sufficiency principle, tend to produce misleading impressions of ignorance. Bob recognizes that his epistemic position with respect to the cinnamon proposition makes it improper to assert that proposition in his conversation with Alice, and accepts that being in a position to know is sufficient for being in a position to assert. Insensitivity to the distinction between $\left({ }^{*} \mathrm{~B}\right)$ and $\left({ }^{*} \mathrm{~N}\right)$ thus leads to the impression that the cinnamon proposition is unknown. ${ }^{24}$

\section{THE UNASSERTABILITY SOLUTION AND THE DESIDERATA}

The unassertability solution predicts that a high stakes speaker who recognizes that she is not in a position to assert that $\mathrm{p}$ will tend to judge that she is not in a position to know that $\mathrm{p}$ : the appearance of ignorance is grounded in a recognition that her epistemic position is insufficient for assertability, which leads, via the sufficiency principle, to the judgment that she is not in a position to know (Position to Know). We should expect that subjects who make such a judgment will regard the literal contents of their knowledge denials as true (Semantics), and that these contents will appear true even in thought (Thought). Since the judgment stems from an accurate appraisal of the speaker's own epistemic position - in particular, that her position is insufficient for proper assertion - it is one we should expect epistemically responsible speakers to make (Responsibility), and to involve no overestimation of her epistemic risks (Accuracy).

Finally, the solution predicts that subjects in the same epistemic position as the speaker will also appear not to be in a position to know (Projection). A high stakes subject who succumbs to the error posited by the unassertability solution thinks that her epistemic position is insufficient for knowing. Whatever weakness in her own epistemic position presents an apparent block to knowing will also appear to prevent another subject in the same epistemic position from knowing. So we should expect her to treat any subject whose epistemic position she takes to be equivalent to her own as also not being in a position to know. The unassertability solution thus predicts that first-person and third-person judgments about knowledge and ignorance will sway together.

\section{THE SOLITARY APPEARANCE OF IGNORANCE}

Like most widely known cases mustered as evidence against traditionalism, those of Carol and Bob center on conversations, and so provide the raw materials for the unassertability

24 Though my focus is on the misleading appearance of ignorance in high stakes situations, the unassertability solution can be extended to cases where stakes are not a factor. For example, fallibilists allow that a subject can know that $\mathrm{p}$ without having decisive evidence against various far-fetched skeptical hypotheses. In some conversational settings, though, an assertion that $\mathrm{p}$ may constitute a wholesale dismissal of such far-fetched hypotheses. If one's epistemic position with respect to $\mathrm{p}$ is insufficient to warrant such a dismissal, assertion is liable to be epistemically improper. Correctly sensing that asserting p would be epistemically improper, the speaker and her interlocutors, blind to the fact that her assertion would be merely broadly improper but aware of the sufficiency of knowledge for epistemically proper assertion, would experience the misleading appearance that she is not in a position to know that $\mathrm{p}$. 
solution to work with. But what about situations where assertion is not an issue?25 Suppose that Bob doesn't learn of Ted's cinnamon allergy from Alice, but discovers in solitude that he himself has the dangerous condition. If, considering his own epistemic situation, he judges that he is not in a position to know the cinnamon proposition, then he has made an error by the moderate traditionalist's lights. And yet he is not contemplating an assertion of that proposition. A high stakes error that is not rooted in a judgment about the epistemic propriety of an assertion isn't explained by the unassertability solution. What should we say about such cases?

First, it is not altogether clear that a subject privately contemplating the question of $\mathrm{p}$ is not considering an assertion that $\mathrm{p}$. Solitary deliberation about $\mathrm{p}$ is most readily imagined as an internal dialogue concerning $\mathrm{p}$. It is natural to think that an internal dialogue that issues in a judgment that $\mathrm{p}$ ends in a private assertion that $\mathrm{p}$. So even subjects merely wondering whether $\mathrm{p}$ may be contemplating an assertion that $\mathrm{p}$; i.e., an assertion of $\mathrm{p}$ to themselves. If judgment is a species of assertion, then we could apply the unassertability account to cases not involving conversation. However, even granting the thesis that solitary judgment is a species of assertion, the unassertability account could only handle such cases if a judgment that $\mathrm{p}$ would also constitute an act that the subject's epistemic position with respect to $\mathrm{p}$ does not warrant.

Still, the unassertability solution illuminates a path for explaining the solitary appearance of ignorance. The solution implements a more general strategy. The general strategy starts by identifying a principle on which being in a position to know that $\mathrm{p}$ is sufficient for epistemically proper $\varphi$-ing. In a case where there is no practical difference between $\varphi$-ing and $\psi$-ing, but to $\psi$ would be improper due to a weakness in one's epistemic position with respect to $\mathrm{p}$, acceptance of the principle can generate the misleading appearance of ignorance. A subject who is sensitive to the fact that $\varphi$-ing would be epistemically improper due to a weakness in her epistemic position and fails to distinguish between $\varphi$-ing and $\psi$-ing can be led by the principle to judge that she isn't in a position to know $\mathrm{p}$. The unassertability account results when $\varphi$-ing is asserting that $\mathrm{p}$ and $\psi$-ing is some other conversational act that would be performed by an assertion that $\mathrm{p}$. But the strategy can be implemented in other ways. Here is one possibility:

Prescinding from the characterization of judgment as a private form of assertion, it is plausible that being in a position to know that $\mathrm{p}$ is sufficient for epistemically proper judging that $\mathrm{p}$ : if you're in a position to know that $\mathrm{p}$, you're in a position to judge that $\mathrm{p}$. In some circumstances, though, there may be no practical difference between a judgment that $\mathrm{p}$ and a distinct cognitive act one is not in a position to perform. And in particular, an epistemically proper judgment that $\mathrm{p}$ may not be practically distinct from a cognitive act one's epistemic position with respect to $\mathrm{p}$ does not warrant. For example, when I am knowingly presented with a choice that will result in my death if $p$ is false, there may be no practical difference between judging that $\mathrm{p}$ and resolving to risk my life on my being correct about $\mathrm{p}$. But I can know that $\mathrm{p}$ without its being epistemically proper for me to risk my life on the question of whether p. ${ }^{26}$ Moreover, when I am not in an epistemic position to risk my life on $\mathrm{p}$, that's partly because of a weakness in my epistemic

25 This excellent question was posed by an anonymous referee.

26 This idea is widely accepted among moderates; e.g., Fantl and McGrath defend their conception of fallibilism partly by appeal to cases where one knows that $\mathrm{p}$ but it would not be rational to stake one's life on p (Fantl and McGrath 2009: I3). 
position with respect to $p$ : properly staking one's life on p requires being in a stronger epistemic position with respect to $\mathrm{p}$ than most of us are with respect to many propositions we are in a position to know. A subject who recognizes that by judging that $\mathrm{p}$ she would stake her life on $\mathrm{p}$, and that her epistemic position with respect to $\mathrm{p}$ makes such a risk epistemically improper, will, if she treats being in a position to know as sufficient for epistemically proper judging, be susceptible to the misleading appearance of ignorance in a way closely analogous to that described by the unassertability account. It is not difficult to fit the solitary version of Bob's high-stakes impression of ignorance into this suggestion.

\section{IO. CONCLUSION}

In sections 5 and 6 , I argued that the distinction between narrow and broad propriety neutralizes the threat that the sufficiency principle poses to moderate traditionalism. Then in sections 7 and 8, I used that distinction to develop an explanation for the apparent loss of knowledge in high stakes situations. Since we don't ordinarily draw the distinction between narrow and broad propriety, our acceptance of the sufficiency principle leads, in high stakes situations, to the misleading appearance of ignorance.

Important questions remain to be addressed on behalf of the unassertability solution. One is to give an explanation of the conversational dynamics that result in a high stakes speaker's assertion constituting an act she is not in a position to perform. Turri's proposal about guaranteeing is not unproblematic, and we didn't explore in depth the other suggestions made at the end of that section, nor that made in section 9 to account for the solitary appearance of ignorance. Another is to offer an explanation for how a weakness in your epistemic position with respect to $\mathrm{p}$ could make it epistemically improper to act even though you are in a position to know that $\mathrm{p}$. This claim stands in prima facie tension with the popular principle that knowing that $\mathrm{p}$ allows you to treat $\mathrm{p}$ as a reason for acting. ${ }^{27}$ But moderate traditionalists need to address this tension anyway: when the stakes get high enough, even subjects in very strong epistemic positions with respect to p seem blocked from treating $\mathrm{p}$ as true for the sake of deliberation. The unassertability solution's ability to predict and explain all of the features of the most problematic examples of the high stakes appearance of ignorance gives moderate traditionalists an additional motivation for clarifying the relationship between knowledge and epistemically permissible action. $^{28}$

Ichikawa (2OI2) calls this the knowledge norm of practical reasoning, and draws an important distinction between its being appropriate to treat $\mathrm{p}$ as a reason for acting and p's rationalizing an action. In terms of Ichikawa's distinction, the question is: what accounts for cases where your epistemic position with respect to $\mathrm{p}$ puts you in a position to treat $\mathrm{p}$ as a reason for acting, but is too weak for $\mathrm{p}$ to rationalize your action? For related principles, see Hawthorne and Stanley's (2009) 'Reasons-Knowledge Principle' and Fantl and McGrath's (2009) principle KJ.

28 Thanks to Troy Cross and Mylan Engel for feedback on earlier drafts of this paper, and an anonymous referee for very fruitful comments. 


\section{REFERENCES}

Austin, J. L. I962. How to Do Things With Words. Oxford: Oxford University Press.

Ayer, A. J. 1956. The Problem of Knowledge. London: Macmillan.

Bach, K. 2005. 'The Emperor's New 'Knows'.' In G. Preyer and G. Peter (eds), Contextualism in Philosophy: On Epistemology, Language and Truth, pp. 5 I-90. Oxford: Oxford University Press.

- 2008. 'Applying Pragmatics To Epistemology.' Philosophical Issues, i 8: 68-88.

Bertolet, R. I994. 'Are There Indirect Speech Acts?' In S. Tsohatzidis (ed.), Foundations of Speech Act Theory: Philosophical and Linguistic Perspectives, pp. 335-49. London: Routledge.

Black, T. 2005. 'Classic Invariantism, Relevance and Warranted Assertibility Manoeuvres.' The Philosophical Quarterly, 55:328-36.

Brogaard, B. 2008. 'In Defense of a Perspectival Semantics for 'Know'.' Australasian Journal of Philosophy, 86: 439-59.

Brown, J. 2006. 'Contextualism and Warranted Assertibility Manoeuvres.' Philosophical Studies, I30: $407-35$.

- 2010. 'Knowledge and Assertion.' Philosophy and Phenomenological Research, 8I: 549-66.

- 20I3. 'Experimental Philosophy, Contextualism, and SSI.' Philosophy and Phenomenological Research, 86: 233-6I.

Cohen, S. 1988. 'How to be a Fallibilist.' Philosophical Perspectives, 2: 9I-I 23.

Danto, A. I973. Analytical Philosophy of Action. Cambridge: Cambridge University Press.

DeRose, K. 2002. 'Assertion, Knowledge, and Context.' Philosophical Review, I I I: 167-203.

- 2009. The Case for Contextualism. Oxford: Oxford University Press.

- 20 I I. 'Contextualism, Contrastivism, and X-Phi Surveys.' Philosophical Studies, I 5 6: 8 I-I Io.

Douven, I. 2006. 'Assertion, Knowledge, and Rational Credibility.' Philosophical Review, i I 5: $449-85$.

Fantl, J. and McGrath, M. 2009. Knowledge in an Uncertain World. Oxford: Oxford University Press.

Grimm, S. 20 I I. 'On Intellectualism in Epistemology.' Mind, г 20: 705-33.

Hawthorne, J. 2004. Knowledge and Lotteries. Oxford: Oxford University Press.

Hawthorne, J. and Stanley, J. 2009. 'Knowledge and Action.' Journal of Philosophy, I05: 57 I-90.

Hazlett, A. 2007. 'Grice's Razor.' Metaphilosophy, 38: 669-90.

Iacono, L. 2008. 'Warranted Assertability Maneuvers and The Rules Of Assertion.' Pacific Philosophical Quarterly, 89: 460-9.

Ichikawa, J. 20I2. 'Knowledge Norms and Acting Well.' Thought, I: 49-55.

Knobe, J. and Schaffer, J. 20I 2. 'Contrastive Knowledge Surveyed.' Nous, 46: 675-708.

Kvanvig, J. 2009. 'Assertion, Knowledge, and Lotteries.' In P. Greenough and D. Pritchard (eds), Williamson on Knowledge, pp. I40-60. Oxford: Oxford University Press.

Lackey, J. 20 I I. 'Assertion and Isolated Secondhand Knowledge.' In J. Brown and H. Cappelen (eds), Assertion, pp. 25I-75. Oxford: Oxford University Press.

Lewis, D. 1996. 'Elusive Knowledge.' Australasian Journal of Philosophy, 74: 549-67.

MacFarlane, J. 2005. 'The Assessment Sensitivity of Knowledge Attributions.' Oxford Studies in Epistemology, I: 197-234.

- 2009. 'Non-Indexical Contextualism.' Synthese, I66: 23 I-50.

Nagel, J. 2008. 'Knowledge Ascriptions and the Psychological Consequences of Changing Stakes.' Australasian Journal of Philosophy, 86: 279-94.

- 2010. 'Knowledge Ascriptions and the Psychological Consequences of Thinking about Error.' The Philosophical Quarterly, 60: 286-306.

- 201 I. 'Epistemic Anxiety and Adaptive Invariantism.' Philosophical Perspectives, 24: 407-35.

Peels, R. 2010. 'What is Ignorance?' Philosophia, 38: 57-67.

Pynn, G. Forthcoming. 'Sensitivity and Assertibility.' Acta Analytica. doi: I0.I007/ SI2I36-OI3-O2I2-6.

Rysiew, P. 200I. 'The Context-Sensitivity of Knowledge Attributions.' Nous, 35: 477-5 I4.

- 2007. 'Speaking of Knowing.' Nous, 4I: 627-62.

Sandis, C. 20I0. 'Basic Actions and Individuation.' In T. O'Connor and C. Sandis (eds), A Companion to the Philosophy of Action, pp. IO-I7. Malden, MA: Wiley-Blackwell. 
Schaffer, J. 2005. 'What Shifts? Thresholds, Standards, or Alternatives?' In G. Preyer and G. Peter (eds), Contextualism in Philosophy: On Epistemology, Language and Truth, pp. II 5-30. Oxford: Oxford University Press.

- 2008. 'Knowledge in the Image of Assertion.' Philosophical Issues, I8: I-I9.

Schroeder, M. 20I 2. 'Stakes, Withholding, and Pragmatic Encroachment.' Philosophical Studies, I 60: $265-85$.

Searle, J. 1969. Speech Acts: An Essay in The Philosophy Of Language. Cambridge: Cambridge University Press.

Stainton, R. 20I0. 'Contextualism in Epistemology and the Context Sensitivity of 'Knows'.' In J. C. Campbell, M. O'Rourke and H. Silverstein (eds), Knowledge and Skepticism: Topics in Contemporary Philosophy, Vol. 5, pp. I I3-39. Cambridge, MA: MIT Press.

Stanley, J. 2005. Knowledge and Practical Interests. Oxford: Oxford University Press.

- . 2008. 'Knowledge and Certainty.' Philosophical Issues, I 8: 35-57.

Turri, J. 20I0. 'Epistemic Invariantism and Speech Act Contextualism.' Philosophical Review, i 19: 77-95.

Unger, P. 1975. Ignorance. Oxford: Oxford University Press.

Weiner, M. 2005. 'Must We Know What We Say?' Philosophical Review, II4: 227-5I.

Williamson, T. 2000. Knowledge and its Limits. Oxford: Oxford University Press.

- 2005. 'Contextualism, Subject-Sensitive Invariantism and Knowledge of Knowledge.' The Philosophical Quarterly, 55: 213-35.

GeOFF PyNN is assistant professor of philosophy at Northern Illinois University. His main areas of research are epistemology and philosophy of language. 